OPEN ACCESS

Edited by:

Elisabeth Utens,

Sophia Children's Hospital,

Netherlands

Reviewed by:

Muhammad Ali Mumtaz,

Baylor College of Medicine, USA

Federico Gutierrez-Larraya, Hospital Universitario La Paz, Spain

*Correspondence:

Ulrike M. M. Bauer

ubauer@kompetenznetz-ahf.de

Specialty section:

This article was submitted to

Pediatric Cardiology,

a section of the journal

Frontiers in Pediatrics

Received: 17 November 2016

Accepted: 02 May 2017

Published: 19 May 2017

Citation:

Helm PC, Kaemmerer $H_{\text {, }}$ Breithardt G, Sticker EJ, Keuchen $R$, Neidenbach R, Diller G-P, Tutarel O and Bauer UMM (2017) Transition in

Patients with Congenital Heart

Disease in Germany: Results of a Nationwide Patient Survey.

Front. Pediatr. 5:115.

doi: 10.3389/fped.2017.00115

\section{Transition in Patients with Congenital Heart Disease in Germany: Results of a Nationwide Patient Survey}

\author{
Paul C. Helm ${ }^{1,2}$, Harald Kaemmerer ${ }^{3}$, Günter Breithardt ${ }^{4,5}$, Elisabeth J. Sticker ${ }^{6}$, \\ Roland Keuchen ${ }^{7}$, Rhoia Neidenbach ${ }^{3}$, Gerhard-Paul Diller ${ }^{4,5}$, Oktay Tutarel ${ }^{3}$ \\ and Ulrike M. M. Bauer ${ }^{1,2,5 *}$
}

\begin{abstract}
${ }^{1}$ National Register for Congenital Heart Defects, Berlin, Germany, ${ }^{2}$ DZHK (German Centre for Cardiovascular Research), Berlin, Germany, ${ }^{3}$ Department of Paediatric Cardiology and Congenital Heart Disease, German Heart Centre Munich, Technical University of Munich, Munich, Germany, ${ }^{4}$ Division of Adult Congenital and Valvular Heart Disease, Department of Cardiovascular Medicine University Hospital of Münster, Münster, Germany, ${ }^{5}$ Competence Network for Congenital Heart Defects, Berlin, Germany, ${ }^{6}$ Department of Psychology, University of Cologne, Cologne, Germany, ${ }^{7}$ Bundesvereinigung JEMAH e. V., Aachen, Germany
\end{abstract}

Background: A growing number of adults with congenital heart disease (ACHD) pose a particular challenge for health care systems across the world. Upon turning into 18 years, under the German national health care system, ACHD patients are required to switch from a pediatric to an adult cardiologist or an ACHD-certified provider. To date, reliable data investigating the treatment situation of $\mathrm{ACHD}$ patients in Germany are not available.

Materials and methods: An online survey was conducted in collaboration with patient organizations to address the life situation and the conditions of health care provision for ACHD patients in Germany. ACHD patients were recruited from the database of the National Register for Congenital Heart Defects (NRCHD) and informed about the survey via email, websites, and social networks. A total of 1,828 ACHD patients (1,051 females) participated in this study. The mean age was $31.7 \pm 11.7$ years. Participants were surveyed about treating physicians and the institution mainly involved in the treatment of their CHD. In addition, participants were asked questions to assess the level of trust toward their treating physician and their familiarity with the term "ACHD-certified provider."

Results: Among the surveyed patients, $25.4 \%$ stated that they attended a specific ACHD clinic at a heart center regularly, $32.7 \%$ were treated in a private practice setting by a pediatric cardiologist, $32.4 \%$ in a private practice (adult) cardiology setting, and 9.5\% were treated by an "other physician." Only $24.4 \%$ of the male and $29.7 \%$ of the female ACHD patients were familiar with the term "ACHD-certified provider."

Conclusion: The transfer from pediatric cardiology to ACHD care requires further attention as many adult patients have not transferred to certified ACHD providers. The question of whether ACHD patients in Germany are offered consistent and adequate care 
should also be investigated in more detail. The answers regarding the ACHD certification are particularly disappointing and indicative of a large information gap and inadequate education in clinical practice.

Keywords: transition, congenital heart disease, online survey, adult with congenital heart disease, treatment, lost to follow-up, National Register for Congenital Heart Defects

\section{INTRODUCTION}

About 6,000 children are born with congenital heart disease (CHD) in Germany each year (1). The number of adults with $\mathrm{CHD}$ (ACHD) is growing constantly $(2,3)$. Due to major advances of diagnosis and treatment, more than $90 \%$ of all children born with CHD reach adulthood today in western countries (2-6). The growing number of ACHD patients is a particular challenge for health care systems worldwide $(7,8)$. With increasing age, the medical needs of these patients are changing and motivate the need for a specific transition program (9). In this context, the term "transition" refers to the transitory stage from child-oriented care to a type of medical care that meets the requirements of adult patients (10).

Throughout their lives, patients with CHD have special medical and emotional needs. Thus, a successful transition from pediatric to adult centered care is particularly important $(11,12)$.

In 2010, the European Society of Cardiology (ESC) published practical guidelines for the management of ACHD (13). These guidelines, however, do not give specific recommendations regarding organization of ACHD care or further training for physicians $(7,13)$. It is accepted that ACHD patients have special needs requiring their treating physicians to have special expertise and training in the field of CHD in order to offer adequate care $(4,13-22)$. In Germany, certified heart centers and certified cardiologists/pediatric cardiologists in private practice, offering care tailored specifically to ACHD patients $(23,24)$ hold a certificate for "ACHD specialization." The process for awarding "ACHD certification" has been standardized as a result of a cooperation within a joint task force that includes the German associations of cardiology, pediatric cardiology, and cardiothoracic/vascular surgery, as well as professional associations and patient organizations $(23,24)$.

Until their 18th year of life, patients are usually treated by pediatric cardiologists in private practice, heart centers, or university hospitals. According to the regulations of the German Medical Association, child and adolescent medicine, which includes pediatric cardiology, is responsible for treating infants, toddlers, children, and adolescents (25). The 19th year of life usually marks the end of adolescence (Youth Courts Law, par. 1, Social Act 8, par. 7 sections 1 and 2) (26,27). As of this age, patients usually cannot be treated by a pediatrician any more.

Representative data regarding the question of who mainly treats ACHD patients in Germany for their CHD are not available. The present study aims to shed light on the treatment situation of ACHD patients in Germany and specifically answer the question of whether transition is successful or not. The answers to these questions are highly relevant not only in terms of adequate health care provision and policy but also for optimizing support for CHD patients and their relatives throughout their lives.

\section{MATERIALS AND METHODS}

The National Register for Congenital Heart Defects (NRCHD) conducted an online survey in collaboration with the two patient organizations "Bundesverband Herzkranke Kinder e. V." (BVHK) and "Bundesvereinigung Jugendliche und Erwachsene mit angeborenem Herzfehler" (BV JEMAH). The survey's primary objective was to collect information on the general life situation and the conditions of health care of ACHD patients in Germany.

With 51,134 members (as of October 2016), the NRCHD is Europe's largest register of CHD. It is representative of the German cohort of patients with CHD (28). For patient recruitment, the register's database was searched for patients who were 18 years or older at the time of the survey and for whom an email address was available. Respective individuals were invited to take part in the survey via email. In addition, the NRCHD, BVHK, and BV JEMAH informed ACHD patients about the survey via websites and social media channels.

Questions asked included:

- Which kind of physician mainly treats you for your heart disease?

- Do you attend regular follow-up examinations at a heart center/university hospital?

- Is the physician who mainly treats you for your heart disease ACHD-certified?

- Would you rather be treated by a pediatric cardiologist or an adult cardiologist?

Furthermore, four rating questions were asked using a six-tier scale for analysis:

- Do you understand the explanations given by your physician concerning your heart defect?

- Do you feel well-informed about your heart defect by your treating physician?

- How well do you rate your knowledge regarding your heart defect?

- How much do you trust your treating physician?

The six-tier scales were divided into three categories:

- $1-2=$ low/negative rating

- 3-4 = medium/neutral rating

$-5-6=$ high/positive rating.

For compiling the online questionnaire, the software EFS survey was used (29).

The respondents' statements regarding their own CHD diagnosis were assigned to four groups according to Bethesda criteria (14).

The NRCHD has extensive experience in data collection via online surveys. The established data infrastructure of the NRCHD 
allows for storing data within the framework of an own data protection concept, which is registered with the Berlin Official for Data Protection and Freedom of Information (No. 531.390). General approval by the Ethics Committee Charité Berlin is available for all research conducted within the scope of the NRCHD. Registration to the NRCHD is voluntary. Participation is based on a broad consent. Patients agree that the NRCHD obtains and stores medical data from their attending physicians, for use in ongoing and future research studies until withdrawal. By consenting to this, patients have the option of taking part in studies and of regularly receiving information on the current state of research studies in the field of CHD via the patient website "www.herzregister.de." The above Ethics Committee has approved the NRCHD ethical concept in 1999 and 2011. Participation in the NRCHD is promoted by patients' and parents' associations through their websites and in print.

\section{Statistical Analysis}

The chi-square test was used for group comparisons including nominal data; data that were at least ordinally scaled were analyzed by using the Mann-Whitney $U$ test or, in the case of more than two comparison groups, the Kruskal-Wallis test. Alpha error adjustment in multiple comparisons (30) was not performed as this was mainly an explorative and descriptive study and to avoid overlooking potential influencing factors.

SPSS (version 22) was used for all statistical analyses (31).

\section{RESULTS}

A total of 1,828 individuals participated. The mean age was 31.7 years ( \pm 11.7 years) and $57.5 \%$ of patients were female (Table 1).

\section{Underlying Heart Defect}

At the beginning of the survey, the participants were asked to provide information regarding their CHD. Based on this information, patients were assigned to four diagnostic groups: simple CHD $(n=398)$, moderate CHD $(n=606)$, complex CHD $(n=699)$, and non-classifiable CHD $(n=125)$ (Table 1).

\section{Who Treats ACHD in Germany?}

Overall, $58.1 \%$ of those surveyed were treated mainly at specific ACHD clinics at a heart center or by a pediatric cardiologist in private practice. Significant gender differences $(p<0.05)$ were found: women were more often treated at specific ACHD clinics at heart centers. Significant differences $(p<0.001)$ were also found between groups of CHD severity: In 70.5\% of all cases, patients with complex CHD and in $43.5 \%$ of all cases, patients with simple CHD were treated mainly at a specific ACHD clinic at a heart center or by a pediatric cardiologist in private practice. More detailed information can be found in Table 2 .

\section{Regular Follow-up at a Specialized ACHD Clinic at a Heart Center}

The majority of respondents (53.8\%) stated that they attend a specific ACHD clinic at a heart center for a follow-up examination at least once a year (Table 2). Significant gender differences were not detected. However, significant differences $(p<0.001)$ according to CHD severity were found: While $71.1 \%$ of patients with complex $\mathrm{CHD}$ attended a specialized ACHD clinic at a heart center at least annually, only $24.1 \%$ of patients with simple CHD did so (Table 2).

\section{ACHD Certification of the Mainly Treating Physician}

The majority of respondents $(66.1 \%)$ stated that they did not know if the physician mainly treating them for their CHD was ACHD-certified. Significant gender differences $(p<0.05)$ were found: $29.7 \%$ of the female participants possessed knowledge about the ACHD certification status of their mainly treating physician compared to $25.4 \%$ of the male participants. Also in this case, patients with complex CHD were best informed regarding the their physician's ACHD certification status, with $39.9 \%$ possessing knowledge, compared to participants with less complex disease (Table 2).

\section{Patient Preferences for Particular Physicians}

Overall, $28.5 \%$ of those surveyed stated a preference for being treated by a pediatric cardiologist in private practice. Out of these, only $55.7 \%$ are actually treated mainly by a pediatric cardiologist in private practice. Thirty percent would prefer a treatment by an adult cardiologist in private practice (see Table 2), while $58.3 \%$ of these are actually treated in this setting. Furthermore, 7.9\% of those surveyed stated not to know the difference between pediatric cardiology and adult cardiology, while $33.5 \%$ did to not care who mainly treats them (Table 2).

Significant gender differences $(p<0.05)$ were found. Female participants rather preferred treatment by a pediatric cardiologist

TABLE 1 | Sample composition $(N=1,828)$.

\begin{tabular}{|c|c|c|c|c|c|}
\hline & $\%(N)$ & Age & Full-time employment & High education level & In a relationship \\
\hline Total & $100(1,828)$ & $31.7 \pm 11.7$ & $37.3 \%(681)$ & $32.4 \%(592)$ & $61.7 \%(1.128)$ \\
\hline Male & $42.5(777)$ & $32.7 \pm 12.6$ & $49.3 \%(383)$ & $36.7 \%(285)$ & $56.9 \%(442)$ \\
\hline Female & $57.5(1,051)$ & $31 \pm 11$ & $28.4 \%(298)$ & $29.3 \%(307)$ & $65.3 \%(686)$ \\
\hline Simple congenital heart disease (CHD) & $21.8(398)$ & $33.4 \pm 14.2$ & $40.2 \%(160)$ & $34.2 \%(136)$ & $67.3 \%(268)$ \\
\hline Moderate $\mathrm{CHD}$ & $33.2(606)$ & $31.1 \pm 10.7$ & $41.4 \%(251)$ & $37.8 \%(229)$ & $62.9 \%(381)$ \\
\hline Complex CHD & 38.2 (699) & $32.2 \pm 11.1$ & $33.2 \%(232)$ & $28.4 \%(199)$ & $58.5 \%(409)$ \\
\hline Unclassified CHD & $6.8(125)$ & $26.7 \pm 10$ & $30.4 \%(38)$ & $22.4 \%(27)$ & $56 \%(70)$ \\
\hline
\end{tabular}

$N$, sample size. 
TABLE 2 | Descriptive statistics (subjective patient statements).

Which kind of physician mainly treats you for your heart disease?

\begin{tabular}{|c|c|c|c|c|c|c|c|}
\hline & Total $(\mathrm{N}=\mathbf{1 , 8 2 8})$ & Male $(n=777)$ & Female $(n=1,051)$ & Simple CHD $(n=398) A$ & $\begin{array}{l}\text { Moderate CHD } \\
\quad(n=606) B\end{array}$ & $\begin{array}{l}\text { Complex CHD } \\
(n=699) C\end{array}$ & $\begin{array}{l}\text { Others/unclassified } \\
\text { CHD }(n=125) D\end{array}$ \\
\hline $\begin{array}{l}\text { Adults with congenital heart disease (ACHD) } \\
\text { clinic at a heart center }\end{array}$ & $25.4 \%(n=465)$ & $23.3 \%(n=181)$ & $27 \%(n=284)$ & $19.1 \%(n=76)$ & $23,1 \%(n=140)$ & $33,2 \%(n=232)$ & $13.6 \%(n=17)$ \\
\hline Pediatric cardiologist in private practice & $32.7 \%(n=598)$ & $33.1 \%(n=257)$ & $32.4 \%(n=341)$ & $24.4 \%(n=97)$ & $34 \%(n=206)$ & $37,3 \%(n=261)$ & $27.2 \%(n=34)$ \\
\hline Adult cardiologist in private practice & $32.4 \%(n=592)$ & $32.3 \%(n=251)$ & $32.4 \%(n=341)$ & $38.4 \%(n=153)$ & $36,8 \%(n=223)$ & $23,2 \%(n=162)$ & $43.2 \%(n=54)$ \\
\hline Another physician & $9.5 \%(n=173)$ & $11.3 \%(n=88)$ & $8.1 \%(n=85)$ & $18.1 \%(n=72)$ & $6,1 \%(n=37)$ & $6,3 \%(n=44)$ & $16 \%(n=20)$ \\
\hline Group differences & & \multicolumn{2}{|c|}{${ }^{* \star \star} p<0.05$} & \multicolumn{4}{|c|}{${ }^{* *} p<0.001$ (A vs. B: ${ }^{* \star} p<0.001$; A vs. C: ${ }^{* \star *} p<0.001$; B vs. $C:{ }^{* * *} p<0.001$; B vs. D: } \\
\hline
\end{tabular}

${ }^{* \star *} p<0.001 ;$ C vs. D: $\left.{ }^{* \star \star} p<0.001\right)$

Do you attend regular follow-up examinations at a heart center/university hospital?

\begin{tabular}{|c|c|c|c|c|c|c|c|}
\hline & Total $(N=1,828)$ & Male $(n=777)$ & Female $(n=1,051)$ & Simple CHD $(n=398) A$ & $\begin{array}{c}\text { Moderate CHD } \\
(n=606) B\end{array}$ & $\begin{array}{l}\text { Complex CHD } \\
(n=699) C\end{array}$ & $\begin{array}{l}\text { Others/unclassified } \\
\text { CHD }(n=125) D\end{array}$ \\
\hline At least once a year & $53.8 \%(n=984)$ & $56.8 \%(n=441)$ & $51.7 \%(n=543)$ & $24.1 \%(n=96)$ & $54.1 \%(n=328)$ & $71.1 \%(n=497)$ & $50.4 \%(n=63)$ \\
\hline At least every 2 years & $14 \%(n=256)$ & $12.7 \%(n=99)$ & $14.9 \%(n=157)$ & $16.8 \%(n=67)$ & $16.3 \%(n=99)$ & $10.3 \%(n=72)$ & $14.4 \%(n=18)$ \\
\hline At least every 3 years & $6.4 \%(n=117)$ & $5.4 \%(n=42)$ & $7.1 \%(n=75)$ & $12.3 \%(n=49)$ & $6.9 \%(n=42)$ & $2.7 \%(n=19)$ & $5.6 \%(n=7)$ \\
\hline Less than every 3 years & $20.1 \%(n=368)$ & $20.2 \%(n=157)$ & $20.1 \%(n=211)$ & $36.4 \%(n=145)$ & $18.2 \%(n=110)$ & $12.9 \%(n=90)$ & $18.4 \%(n=23)$ \\
\hline Never visited an ACHD-center & $5.6 \%(n=103)$ & $4.9 \%(n=38)$ & $6.2 \%(n=65)$ & $10.3 \%(n=41)$ & $4.5 \%(n=27)$ & $3 \%(n=21)$ & $11.2 \%(n=14)$ \\
\hline
\end{tabular}

Group differences

${ }^{* *} p<0.001$ (A vs. B: ${ }^{* * *} p<0.001$; A vs. C: ${ }^{* * *} p<0.001$; A vs. D: $p<0.001$; B vs. C:

${ }^{* \star *} p<0.001 ;$ C vs. D: $\left.{ }^{* \star *} p<0.001\right)$

Is the physician who mainly treats you for your heart disease ACHD-certified?

\begin{tabular}{|c|c|c|c|c|c|c|c|}
\hline & Total $(\mathrm{N}=\mathbf{1 , 8 2 8})$ & Male $(n=777)$ & Female $(n=1,051)$ & Simple CHD $(n=398) A$ & $\begin{array}{c}\text { Moderate CHD } \\
(n=606) B\end{array}$ & $\begin{array}{l}\text { Complex CHD } \\
(n=699) C\end{array}$ & $\begin{array}{l}\text { Others/unclassified } \\
\text { CHD }(n=125) D\end{array}$ \\
\hline Yes & $27.8 \%(n=509)$ & $25.4 \%(n=197)$ & $29.7 \%(n=312)$ & $16.1 \%(n=64)$ & $24.8 \%(n=150)$ & $39.9 \%(n=279)$ & $12.8 \%(n=16)$ \\
\hline No & $6.1 \%(n=111)$ & $5.1 \%(n=40)$ & $6.8 \%(n=71)$ & $6.3 \%(n=25)$ & $5.8 \%(n=35)$ & $7 \%(n=49)$ & $1.6 \%(n=2)$ \\
\hline I do not know & $66.15 \%(n=1208)$ & $69.5 \%(n=540)$ & $63.6 \%(n=668)$ & $77.6 \%(n=309)$ & $69.5 \%(n=421)$ & $53.1 \%(n=371)$ & $85.6 \%(n=107)$ \\
\hline Group differences & & \multicolumn{2}{|c|}{${ }^{*} p<0.05$} & \multicolumn{4}{|c|}{${ }^{*} p<0.001$} \\
\hline
\end{tabular}

Would you rather be treated by a pediatric cardiologist or an adult cardiologist?

\begin{tabular}{|c|c|c|c|c|c|c|c|}
\hline & Total $(\mathrm{N}=1,828)$ & Male $(n=777)$ & Female $(n=1,051)$ & Simple CHD $(n=398) A$ & $\begin{array}{c}\text { Moderate CHD } \\
(n=606) B\end{array}$ & $\begin{array}{l}\text { Complex CHD } \\
(n=699) C\end{array}$ & $\begin{array}{l}\text { Others/unclassified } \\
\text { CHD }(n=125) D\end{array}$ \\
\hline Pediatric cardiologist & $28.5 \%(n=521)$ & $25.7 \%(n=200)$ & $30.5 \%(n=321)$ & $16.6 \%(n=66)$ & $25.7 \%(n=156)$ & $38.5 \%(n=269)$ & $24 \%(n=30)$ \\
\hline Adult cardiologist & $30 \%(n=549)$ & $30.2 \%(n=235)$ & $29.9 \%(n=314)$ & $37.2 \%(n=148)$ & $32 \%(n=194)$ & $23.9 \%(n=167)$ & $32 \%(n=40)$ \\
\hline I do not know the difference & $7.9 \%(n=145)$ & $9.7 \%(n=75)$ & $6.7 \%(n=70)$ & $9 \%(n=36)$ & $8.6 \%(n=52)$ & $6 \%(n=42)$ & $12 \%(n=15)$ \\
\hline \multirow[t]{2}{*}{ I do not care } & $33.5 \%(n=613)$ & $34.4 \%(n=267)$ & $32.9 \%(n=346)$ & $37.2 \%(n=148)$ & $33.7 \%(n=204)$ & $31.6 \%(n=221)$ & $32 \%(n=40)$ \\
\hline & & \multicolumn{2}{|c|}{${ }^{*} p<0.05$} & \multicolumn{4}{|c|}{${ }^{*} p<0.001$} \\
\hline
\end{tabular}

$N$, sample size.

*Chi-squared test was used for the statistical analyses.

${ }^{*}$ Kruskal-Wallis test was used for the statistical analyses.

***Mann-Whitney U test was used for the statistical analyses. 
in comparison to male participants (30.5 vs. 25.7\%). Furthermore, significant differences $(p<0.001)$ according to CHD severity were detected: patients with complex CHD preferred pediatric cardiologist in private practice more often $(38.5 \%)$ than patients with simple CHD (16.6\%) (Table 2).

\section{Patient Age and Type of Main Treating Physician}

With increasing age, there was also a change regarding the type of main treating physician. While $45.1 \%$ of the respondents in the youngest age group (18-22 years) were treated mainly by a pediatric cardiologist in private practice, only $17.4 \%$ of the respondents older than 38 years of age were treated in this setting (Figure 1).

\section{Rating Questions}

Significant group differences were found regarding participants' rating of the information about their $\mathrm{CHD}$ that they received by their main treating physician $(p<0.001)$. While only $64.7 \%$ of patients with CHD not treated in a specialist setting felt well well-informed about their condition by their physician, patients treated in a specialist setting more often felt well-informed (pediatric cardiologist in private practice: 79.4\%, ACHD clinic at a heart center: $76.8 \%$, adult cardiologist in private practice: 76.4\%) (Table 3).

Likewise, the question regarding participants' trust in their treating physician yielded significant group differences $(p<0.001)$ (Table 3). The highest degree of trust was reported by those patients who were mainly treated by a pediatric cardiologist (Table 3).

\section{DISCUSSION}

According to the German health care system, patients with CHD may not generally be treated by a pediatric cardiologist in private practice once they have turned 18 years (25). The present study shows indeed, that, with increasing age, patients are less likely to be treated by a pediatric cardiologist in private practice. However, as many as $17.4 \%$ of the patients older than 38 years are still treated by a pediatric cardiologist in private practice. Transition from pediatric to an age-appropriate adult medical care, as defined by the transition concept $(9,10)$, can, therefore, be considered as being only partially successful in Germany based on these results. Adult patients with more complex underlying heart disease are those being mainly treated in a specific ACHD clinic at a heart center or by a pediatric cardiologist in private practice. The relatively large proportion of patients continuing to attend general cardiologists, not specializing in $\mathrm{ACHD}$, supports the concept to provide additional training for adult cardiologists in the field of CHD. To this end, a process of ACHD certification (24) was established in Germany based on recommendations for improving the quality of the interdisciplinary care for ACHD (23). The main intention was to enable, both, pediatric cardiologists to treat adult patients, as well as to provide adult cardiologists with training and experience in the treatment of complex CHD. It is hoped that this addresses the challenges associated with the continuously growing and aging group of CHD patients (14) and ensure that patients receive the necessary support and medical care throughout their lives (24). The fact that a large majority of the surveyed patients did not know the meaning of the term "ACHD-certified," as well as their ignorance regarding the fact of whether their treating physician is actually ACHD-certified, which shows that this certification

\section{Treating physicians}

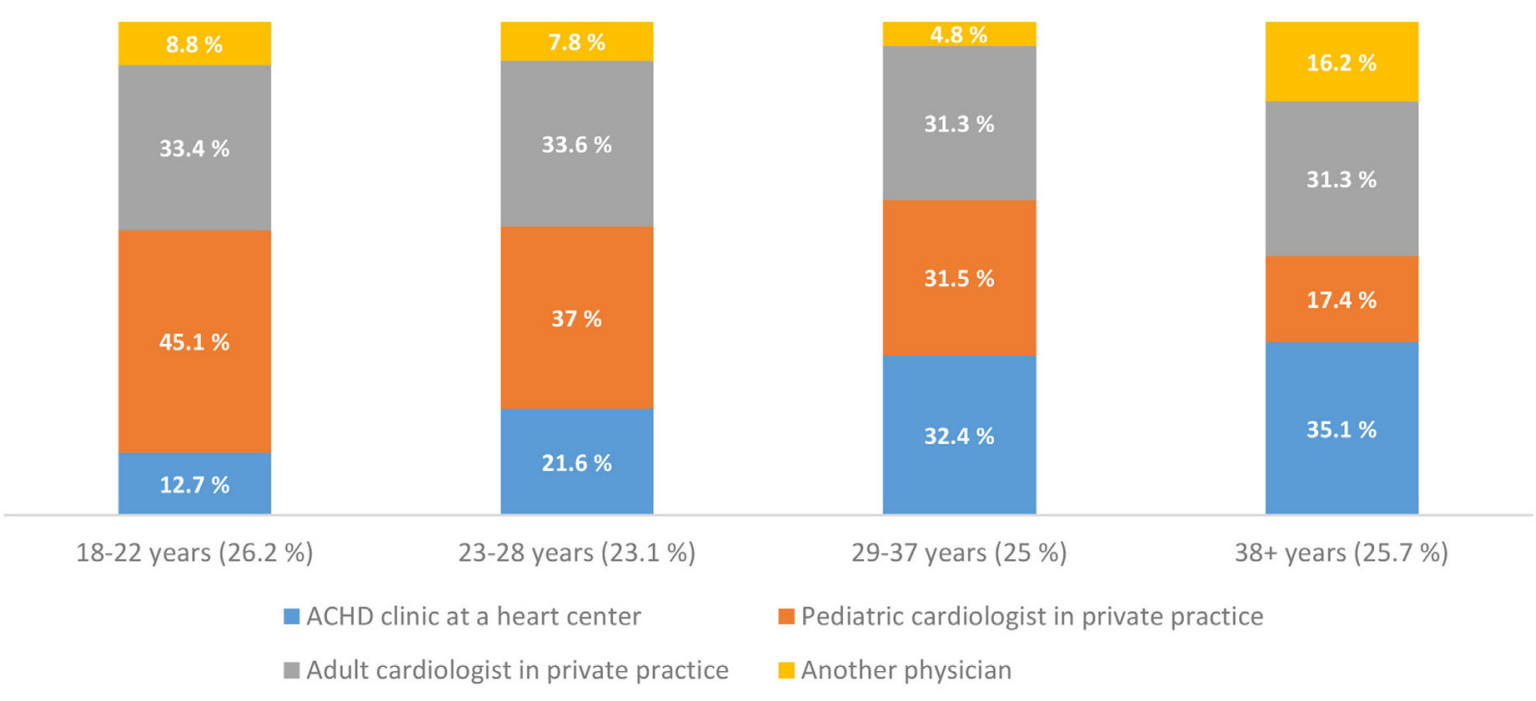

FIGURE 1 | Treating physicians 
TABLE 3 | Descriptive statistics (subjective patient statements).

Do you understand the explanations given by your physician concerning your heart defect?

\begin{tabular}{|c|c|c|c|c|c|}
\hline & Total $(\mathrm{N}=1,828)$ & $\begin{array}{l}\text { ACHD clinic at a heart center } \\
\qquad(n=465) A\end{array}$ & $\begin{array}{l}\text { Pediatric cardiologist in } \\
\text { private practice }(n=598) B\end{array}$ & $\begin{array}{l}\text { Adult cardiologist } \\
\text { in private practice } \\
\qquad(n=592) C\end{array}$ & $\begin{array}{l}\text { Another physician } \\
\qquad(n=173) D\end{array}$ \\
\hline Low & $4 \%(n=73)$ & $3.7 \%(n=17)$ & $4 \%(n=24)$ & $4.2 \%(n=25)$ & $4 \%(n=7)$ \\
\hline Medium & $17.6 \%(n=325)$ & $17.8 \%(n=83)$ & $16.9 \%(n=101)$ & $17.4 \%(n=103)$ & $22 \%(n=38)$ \\
\hline High & $78.2 \%(n=1430)$ & $78.5 \%(n=78,5 \%)$ & $79.1 \%(n=473)$ & $78.4 \%(n=464)$ & $74 \%(n=128)$ \\
\hline Group differences & & & ${ }^{* \star} p=0.583$ & & \\
\hline
\end{tabular}

Do you feel well-informed about your heart defect by your treating physician?

\begin{tabular}{|c|c|c|c|c|c|}
\hline & Total $(\mathrm{N}=1,828)$ & $\begin{array}{l}\text { ACHD clinic at a heart center } \\
\qquad(\mathrm{n}=465) \mathrm{A}\end{array}$ & $\begin{array}{l}\text { Pediatric cardiologist in } \\
\text { private practice }(n=598) B\end{array}$ & $\begin{array}{l}\text { Adult cardiologist } \\
\text { in private practice } \\
\qquad(n=592) C\end{array}$ & $\begin{array}{l}\text { Another physician } \\
\qquad(n=173) D\end{array}$ \\
\hline Low & $4.6 \%(n=85)$ & $4.1 \%(n=19)$ & $3.5 \%(n=21)$ & $4.9 \%(n=29)$ & $9.3 \%(n=16)$ \\
\hline Medium & $19 \%(n=347)$ & $19.1 \%(n=89)$ & $17.1 \%(n=102)$ & $18.8 \%(n=111)$ & $26 \%(n=45)$ \\
\hline High & $76.4 \%(n=1396)$ & $76.8 \%(n=357)$ & $79.4 \%(n=475)$ & $76.4 \%(n=452)$ & $64.7 \%(n=112)$ \\
\hline Group differences & & \multicolumn{4}{|c|}{${ }^{* \star} p<0.001$ (A vs. D: ${ }^{* \star *} p<0.01$; B vs. D: ${ }^{* \star} p<0.001$; C vs. D: $\left.{ }^{* \star *} p<0.01\right)$} \\
\hline
\end{tabular}

How well do you rate your knowledge regarding your heart defect?

\begin{tabular}{|c|c|c|c|c|c|}
\hline & Total $(\mathrm{N}=\mathbf{1 , 8 2 8})$ & $\begin{array}{l}\text { ACHD clinic at a heart center } \\
\qquad(\mathrm{n}=465) \mathrm{A}\end{array}$ & $\begin{array}{l}\text { Pediatric cardiologist in } \\
\text { private practice }(n=598) B\end{array}$ & $\begin{array}{l}\text { Adult cardiologist } \\
\text { in private practice } \\
\qquad(n=592) C\end{array}$ & $\begin{array}{l}\text { Another physician } \\
\qquad(n=173) D\end{array}$ \\
\hline Low & $6.8 \%(n=125)$ & $5.4 \%(n=25)$ & $7 \%(n=42)$ & $6.9 \%(n=41)$ & $9.8 \%(n=17)$ \\
\hline Medium & $38.8 \%(n=710)$ & $35.7 \%(n=166)$ & $41.5 \%(n=248)$ & $39.2 \%(n=232)$ & $37 \%(n=64)$ \\
\hline High & $54.3 \%(n=993)$ & $58.9 \%(n=274)$ & $51.5 \%(n=308)$ & $53.9 \%(n=319)$ & $53.2 \%(n=92)$ \\
\hline Group differences & & & ${ }^{\star \star} p=0.089$ & & \\
\hline \multicolumn{6}{|c|}{ How much do you trust your treating physician? } \\
\hline & Total $(\mathrm{N}=1,828)$ & $\begin{array}{l}\text { ACHD clinic at a heart center } \\
\qquad(\mathrm{n}=465) \mathrm{A}\end{array}$ & $\begin{array}{l}\text { Pediatric cardiologist in } \\
\text { private practice }(n=598) B\end{array}$ & $\begin{array}{l}\text { Adult cardiologist } \\
\text { in private practice } \\
\text { (n=592)C }\end{array}$ & $\begin{array}{l}\text { Another physician } \\
\qquad(n=173) D\end{array}$ \\
\hline Low & $3.2 \%(n=59)$ & $2.4 \%(n=11)$ & $2.2 \%(n=13)$ & $3.7 \%(n=22)$ & $7.5 \%(n=13)$ \\
\hline Medium & $16.8 \%(n=307)$ & $15.5 \%(n=72)$ & $13.2 \%(n=79)$ & $18.9 \%(n=112)$ & $25.4 \%(n=44)$ \\
\hline High & $80 \%(n=1,462)$ & $82.2 \%(n=382)$ & $84.6 \%(n=506)$ & $77.4 \%(n=458)$ & $67.1 \%(n=116)$ \\
\hline Group differences & \multicolumn{5}{|c|}{${ }^{\star \star} p<0.001$ (A vs. D: ${ }^{* \star \star} p<0.001$; B vs. C: ${ }^{* \star *} p<0.01$; B vs. D: ${ }^{* \star \star} p<0.001$; C vs. D: $\left.{ }^{* \star \star} p<0.01\right)$} \\
\hline
\end{tabular}

N, sample size.

${ }^{*}$ Chi-squared test.

${ }^{* *}$ Kruskal-Wallis test.

***Mann-Whitney $U$ test.

measure is not appreciated and understood as a quality criterion by many patients. Therefore, despite the fact that especially patients with complex CHD prefer treatment at specialized ACHD centers, the question of whether the treating physician is ACHD-certified seems to play only a marginal role in choosing a particular center/physician.

One may also question the obligatory shift from pediatric to adult cardiology care in the German health care system. The main problem is that it may prevent a pediatric physician from caring for a patient known to him/her since the patient's early childhood, just because of an age limit that could be regarded by some as arbitrary. This could lead to patients being less compliant with their care. This may be one possible explanation for the major problem of ACHD patients being "lost to follow-up" $(32,33)$. On the other hand, advocates of the transition system rightly argue that adults with CHD have very different needs from children with the conditions requiring particular expertise and training on behalf of the main treating (pediatric-) cardiologist. Resolving the question on the optimal organization of care for ACHD patients is beyond the scope of the current report, but our study provides important insights into the current status of treatment, patient education, and patient views on this topic in a contemporary cohort of German ACHD patients.

\section{Limitations}

Since this is a cross-sectional study, we provide descriptive information and report on associations rather than claiming to report causal relationships between parameters. Moreover, the results reflect respondents' subjective statements. The results may not be applicable to patients outside Germany, since they are affected by the life situation of the patients, as well as the organization of the health care system. 
One might assume that patients registered in the NRCHD have a greater interest in CHD and therefore know more about this condition than German patients who are not registered.

Since the CHD patients have been invited to participate in the survey by emails, via websites and social networks, no reliable response rate can be specified. Therefore, we cannot guarantee that the sample of patients participating in the online survey is representative for the ACHD community at large. However, a previous study has showed that the patient population included in the register is representative. In addition, by involving large national patient organizations, we aimed to increase the reach of the survey and thus also capture patients not necessarily linked to major heart center. This should reduce bias related to more complex patients tending to be more likely associated to tertiary care and thus included in the register.

\section{CONCLUSION}

Reassuringly, ninety percent of the participants were treated by medical specialists. Many patients made use of specific ACHD clinics at a heart center or were seen by pediatric/adult cardiologists in private practice. However, a sizeable proportion of patients was found to not being linked to recognized ACHD specialists, with approximately one-third of all respondents not in continuous medical care at a specific ACHD clinic/

\section{REFERENCES}

1. Schwedler G, Lindinger A, Lange PE, Sax U, Olchvary J, Peters B, et al. Frequency and spectrum of congenital heart defects among live births in Germany. A study of the competence network for congenital heart defects. Clin Res Cardiol (2011) 100:1111-7. doi:10.1007/s00392-011-0355-7

2. Diller G-P, Breithardt G, Baumgartner H. Congenital heart defects in adulthood. Dtsch Arztebl Int (2011) 108:452-9. doi:10.3238/arztebl. 2011.0452

3. Moons P, Bovijn L, Budts W, Belmans A, Gewillig M. Temporal trends in survival to adulthood among patients born with congenital heart disease from 1970 to 1992 in Belgium. Circulation (2010) 122:2264-72. doi:10.1161/ CIRCULATIONAHA.110.946343

4. Marelli AJ, Mackie AS, Ionescu-Ittu R, Rahme E, Pilote L. Congenital heart disease in the general population: changing prevalence and age distribution. Circulation (2007) 115:163-72. doi:10.1161/CIRCULATIONAHA. 106.627224

5. Kovacs AH, Verstappen A. The whole adult congenital heart disease patient. Prog Cardiovasc Dis (2011) 53:247-53. doi:10.1016/j.pcad.2010.11.001

6. Sable C, Foster E, Uzark K, Bjornsen K, Canobbio MM, Connolly HM, et al. Best practices in managing transition to adulthood for adolescents with congenital heart disease: the transition process and medical and psychosocial issues: a scientific statement from the American Heart Association. Circulation (2011) 123:1454-85. doi:10.1161/CIR.0b013e3182107c56

7. Baumgartner H, Budts W, Chessa M, Deanfield J, Eicken A, Holm J, et al. Recommendations for organization of care for adults with congenital heart disease and for training in the subspecialty of 'grown-up congenital heart disease' in Europe: a position paper of the working group on grown-up congenital heart disease of the European Society of Cardiology. Eur Heart J (2014) 35:686-90. doi:10.1093/eurheartj/eht572

8. Cross KP, Santucci KA. Transitional medicine: will emergency medicine physicians be ready for the growing population of adults with congenital heart disease? Pediatr Emerg Care (2006) 22:775-81. doi:10.1097/01. pec.0000245178.13418.4f

9. Lopez KN, Karlsten M, Bonaduce De Nigris F, King J, Salciccioli K, Jiang A, et al. Understanding age-based transition needs: perspectives from adolescents heart center. The trust in the treating physician seems to play a significantly more important role for the surveyed patients than an existing ACHD certification. Overall, there is still a major need for improvement of the (medical) care of ACHD patients.

\section{AUTHOR CONTRIBUTIONS}

PH, HK, GB, ES, RK, RN, G-PD, OT, and UB took responsibility for all aspects of the reliability and freedom from bias of the data presented and their discussed interpretation.

\section{ACKNOWLEDGMENTS}

Our sincere thanks go to all patients and parents who so willingly answered our questions. The authors also thank Anne Gale and Eva Niggemeyer for editorial assistance.

\section{FUNDING}

This work was supported by the Competence Network for Congenital Heart Defects, which received funding from the German Federal Ministry of Education and Research, grant number 01GI0601 (until 2014) and the DZHK (German Centre for Cardiovascular Research; as of 2015).

and adults with congenital heart disease. Congenit Heart Dis (2015) 10:561-71. doi:10.1111/chd.12283

10. Blum RW, Garell D, Hodgman CH, Jorissen TW, Okinow NA, Orr DP, et al. Transition from child-centered to adult health-care systems for adolescents with chronic conditions. A position paper of the society for adolescent medicine. J Adolesc Health (1993) 14:570-6. doi:10.1016/1054139X(93)90143-D

11. Canobbio MM. Health care issues facing adolescents with congenital heart disease. J Pediatr Nurs (2001) 16:363-70. doi:10.1053/jpdn.2001.26570

12. Hudsmith LE, Thorne SA. Transition of care from paediatric to adult services in cardiology. Arch Dis Child (2007) 92:927-30. doi:10.1136/ adc. 2006.103812

13. Baumgartner H, Bonhoeffer P, De Groot NM, de Haan F, Deanfield JE, Galie N, et al. ESC Guidelines for the management of grown-up congenital heart disease (new version 2010). Eur Heart J (2010) 31:2915-57. doi:10.1093/eurheartj/ ehq249

14. Warnes CA, Liberthson R, Danielson GK, Dore A, Harris L, Hoffman JI, et al. Task force 1: the changing profile of congenital heart disease in adult life. J Am Coll Cardiol (2001) 37:1170-5. doi:10.1016/S0735-1097(01)01272-4

15. Moons P, Meijboom FJ, Baumgartner H, Trindade PT, Huyghe E, Kaemmerer $\mathrm{H}$. Structure and activities of adult congenital heart disease programmes in Europe. Eur Heart J (2010) 31:1305-10. doi:10.1093/eurheartj/ehp551

16. Webb GD, Williams RG. Care of the adult with congenital heart disease: introduction. JAm Coll Cardiol (2001) 37:1166. doi:10.1016/ S0735-1097(01)01280-3

17. Deanfield J, Thaulow E, Warnes C, Webb G, Kolbel F, Hoffman A, et al. Management of grown up congenital heart disease. Eur Heart J (2003) 24:1035-84. doi:10.1016/S0195-668X(03)00131-3

18. Kaemmerer H, Bauer U, de Haan F, Flesch J, Gohlke-Barwolf C, Hagl S, et al. Recommendations for improving the quality of the interdisciplinary medical care of grown-ups with congenital heart disease (GUCH). Int J Cardiol (2011) 150:59-64. doi:10.1016/j.ijcard.2010.02.031

19. Hess J, Bauer U, de Haan F, Flesh J, Gohlke-Baerwolf C, Hagl S, et al. Recommendations for adult and paediatric cardiologists on obtaining additional qualification in "adults with congenital heart disease" (ACHD). Int J Cardiol (2011) 149:186-91. doi:10.1016/j.ijcard.2010.01.007 
20. Warnes CA, Williams RG, Bashore TM, Child JS, Connolly HM, Dearani JA, et al. ACC/AHA 2008 guidelines for the management of adults with congenital heart disease: a report of the American College of Cardiology/ American Heart Association task force on practice guidelines (writing committee to develop guidelines on the management of adults with congenital heart disease). Circulation (2008) 118:e714-833. doi:10.1161/ CIRCULATIONAHA.108.190690

21. Silversides CK, Marelli A, Beauchesne L, Dore A, Kiess M, Salehian O, et al. Canadian Cardiovascular Society 2009 consensus conference on the management of adults with congenital heart disease: executive summary. Can J Cardiol (2010) 26:143-50. doi:10.1016/S0828-282X(10) 70355-X

22. Schmaltz AA, Bauer U, Baumgartner H, Cesnjevar R, de Haan F, Franke C, et al. Medical guideline for the treatment of adults with congenital heart abnormalities of the German-Austrian-Swiss Cardiology Specialty Society. Clin Res Cardiol (2008) 97:194-214. doi:10.1007/s00392008-0639-8

23. Kaemmerer H, Breithardt G. Empfehlungen zur Qualitatsverbesserung der interdisziplinaren Versorgung von Erwachsenen mit angeborenen Herzfehlern (EMAH). Clin Res Cardiol (2006) 95(Suppl 4):76-84. doi:10.1007/ s00392-006-2003-1

24. Hess J, Bauer U, de Haan F, Flesch J, Gohlke-Bärwolf C, Hagl S, et al. Empfehlungen für Erwachsenen- und Kinderkardiologen zum Erwerb der Zusatz-Qualifikation "Erwachsene mit angeborenen Herzfehlern" (EMAH). Clin Res Cardiol Suppl (2007) 2:19-26. doi:10.1007/s11789-0060026-9

25. Bundesärztekammer. (Muster-)Weiterbildungsordnung 2003 in der Fassung vom. (2013). Available from: http://www.bundesaerztekammer.de/fileadmin/ user_upload/downloads/20130628-MWBO_V6.pdf

26. JGG - nichtamtliches Inhaltsverzeichnis. (2016). Available from: http://www. gesetze-im-internet.de/jgg/index.html
27. SGB 8-Sozialgesetzbuch(SGB) - Achtes Buch (VIII) - Kinder-und Jugendhilfe(Artikel 1 des Gesetzes v. 26. Juni 1990, BGBl. I S. 1163). (2016). Available from: https://www.gesetze-im-internet.de/sgb_8/BJNR111630990.html

28. Helm PC, Koerten MA, Abdul-Khaliq H, Baumgartner H, Kececioglu D, Bauer UM. Representativeness of the German national register for congenital heart defects: a clinically oriented analysis. Cardiol Young (2015) 26(5):921-6. doi:10.1017/S1047951115001547

29. EFS Survey. Köln: Questback GmbH (2015).

30. Bonferroni CE. Teoria statistica delle classi e calcolo delle probabilita. Firenze: Libreria internazionale Seeber (1936).

31. IBM SPSS Statistics for Windows. Armonk, NY: IBM Corp (2013).

32. Wacker A, Kaemmerer H, Hollweck R, Hauser M, Deutsch MA, BrodherrHeberlein S, et al. Outcome of operated and unoperated adults with congenital cardiac disease lost to follow-up for more than five years. Am J Cardiol (2005) 95:776-9. doi:10.1016/j.amjcard.2004.11.036

33. Mackie AS, Ionescu-Ittu R, Therrien J, Pilote L, Abrahamowicz M, Marelli AJ. Children and adults with congenital heart disease lost to follow-up: who and when? Circulation (2009) 120:302-9. doi:10.1161/ CIRCULATIONAHA.108.839464

Conflict of Interest Statement: The authors declare that the research was conducted in the absence of any commercial or financial relationships that could be construed as a potential conflict of interest.

Copyright (c) 2017 Helm, Kaemmerer, Breithardt, Sticker, Keuchen, Neidenbach, Diller, Tutarel and Bauer. This is an open-access article distributed under the terms of the Creative Commons Attribution License (CC BY). The use, distribution or reproduction in other forums is permitted, provided the original author (s) or licensor are credited and that the original publication in this journal is cited, in accordance with accepted academic practice. No use, distribution or reproduction is permitted which does not comply with these terms. 